\title{
COVID-19 fear and compliance in preventive measures precautions in workers during the COVID-19 pandemic
}

\author{
Esma Kabasakal $^{1}$ (1) $\cdot$ Funda Özpulat $^{2} \cdot$ Ayşegül Akca $^{1} \cdot$ L. Hilal Özcebe ${ }^{3}$
}

Received: 16 September 2020 / Accepted: 5 January 2021 / Published online: 22 March 2021

(c) The Author(s), under exclusive licence to Springer-Verlag GmbH Germany, part of Springer Nature 2021

\begin{abstract}
Objective The aim of the study is to identify the relationship between the fear of COVID-19 and the preventive measures of healthcare workers and service sector employees during the covid-19 pandemic.

Methods The present study is a descriptive type of research. The study's sample group consisted of 735 people and included healthcare workers $(n=426)$ and service sector employees $(n=309)$. In this study, sociodemographic characteristics, employment in the healthcare or service sector, having a relative with COVID-19, losing any relative due to COVID-19 and taking preventive measures were taken as independent variables. The dependent variable was the score from the Fear of COVID-19 Scale (FCV-19S).

Results The FCV-19S median value was 14 for the service sector and 17 for the healthcare sector. While no difference was found between occupational groups and the FCV-19S score in the service sector, there was a significant correlation between occupational groups and the FCV-19S score in the healthcare sector. The FCV-19S median value of midwives was 21, and it was higher than those of other occupational groups were. The mean FCV-19S scores of those who thought they had COVID19 symptoms due to stress or panic were higher among the healthcare workers.

Conclusion The healthcare workers need more support in fear management than those engaged in service sector employees, and it is recommended that raising the awareness of service sector employees in terms of compliance with preventive measures should be prioritized.
\end{abstract}

Keywords COVID-19 $\cdot$ Fear $\cdot$ Healthcare workers $\cdot$ Service sector employees

Esma Kabasakal

esm.akf@gmail.com

Funda Özpulat

funda-ozpulat@hotmail.com

Ayşegül Akca

aysegulakca2014@gmail.com

L. Hilal Özcebe

hilal.ozcebe@gmail.com

1 Faculty of Health Science, Ankara Yıldırım Beyazıt University, Ankara, Turkey

2 Faculty of Health Science, Selçuk University, Konya, Turkey

3 Faculty of Medicine, Public Health Department, Hacettepe University, Ankara, Turkey

\section{Introduction}

Extraordinary situations and epidemics cause fear in society. Fear is an unpleasant emotional state triggered by the detection of threatening stimuli. Fear can affect the behavior of humans and how they intuitively assess the dangers they are exposed to or to which they perceive to be exposed (Rohrmann 2008). Repeated and anticipated events generally do not provoke fear, but anxiety arises if there is uncertainty. The COVID-19 pandemic has affected many people psychologically because of the new situations they have faced in work and social life (Pakpour and Griffiths 2020).

During the COVID-19 pandemic, some workers have been given guidance to work from home with flexible working conditions, while the workload of those who work in the healthcare and services sector has increased even more. Working during the COVID-19 pandemic both increases the likelihood of contracting the disease and affects mental health (Hu et al. 2020). A study with 
healthcare professionals found that $61 \%$ of the participants feared infection because of going to work and $64 \%$ because of their working environment. This fear among individuals who continue to work actively during the COVID-19 pandemic can adversely affect work life. In fact, in the same study, more than $65 \%$ of healthcare workers indicated that their desire not to go to work has been significantly affected by the pandemic (Ogolodom et al. 2020).

Fear can be an instrument for directing individuals to prudent behavior. To eliminate or reduce the fear of COVID-19, individuals are advised to use personal protective equipment (masks, protective clothing, disinfectants, etc.), shower rooms are provided, and change of clothes after work, maintenance of social distancing at work (arrangement of sitting areas), suitably making arrangements in the work environment, and creating safe environments are encouraged (Saleem et al. 2020). Experience from past pandemics suggests that the success of policies to slow down the transmission of a highly contagious disease is associated with the correct perception of personal and social risk factors.

Apart from the health sector, there are employees in other sectors, such as logistics, food, cleaning, and service sectors that are actively working during the pandemic. Workers in these sectors should be able to cope with the fear of the pandemic as well as adhere to measures for protecting their own health and public health. Despite reports in the literature on the level of fear and compliance with measures of the general community or health workers, no data has been found on the level of fear in conjunction with compliance with measures in the current context including service sector employees. In the present study, the relationship between the fear of COVID-19 and the observance of precautions of healthcare workers and service sector employees was investigated. Identifying the level of fear of COVID-19 among employees according to different sociodemographic variables is critical to designing targeted training or prevention programs to overcome the hardships associated with fear and helping individuals engage in preventive behavior. Identifying the current level of fear and observance of precautions is important toward preparing for future pandemics.

\section{Methods}

\section{Research design}

The present study is a descriptive type of research. No sample selection was made in the study, and snowball sampling was used while online survey links were sent to people who agreed to participate in the study.

\section{Criteria for inclusion in the study}

White-collar private-sector workers who continued to work actively during the COVID-19 pandemic, and individuals who participated in voluntary aid groups such as "Vefa Support Group" and "Turkish Red Crescent" if not in gainful employment, thus facing the risk of direct contact with other people, were included in the study.

\section{Sample group}

The study's sample group consisted of 735 people and included healthcare workers $(n=426)$ and service sector employees $(n=309)$. The participants from the healthcare sector included nurses, midwives, physicians, technicians, emergency medical technicians and paramedics, health officers, medical secretaries/officers/patient admission employees, and others (managers, hospital cleaning staff, etc.).

The participants from the service sector were categorized into four groups according to their working styles: (1) Office-workplace workers (workers, engineers, technicians, mechanics, etc.); (2) workers providing home services (cargo employees, water delivery staff, bread delivery staff, etc.); (3) community volunteer workers (Vefa Support Group volunteers and Turkish Red Crescent volunteers); and (4) workers providing services for the community at their workplaces (general store staff, green grocers, butchers, grocers, checkers, cleaners, and stand attendants at bakeries and general stores, etc.)

\section{Research variables}

In this study, sociodemographic characteristics, employment in the healthcare or service sector, having a relative with COVID-19, losing any relative due to COVID-19 and taking measures were taken as independent variables. The dependent variable was the score from the Fear of COVID19 Scale (FCV-19S).

\section{Data collection tools}

Within the scope of the project, the questionnaire included the questions on sociodemographic characteristics of the participants (personal information form), Depression Anxiety Stress Scales-21 (DASS-21), Fear of COVID-19 Scale (FCV-19S), Positive and Negative Mood Questions. In this article, findings regarding personal information form and Fear of COVID-19 Scale (FCV-19S) questions are presented.

Personal Information Form: The form, created by researchers, includes sociodemographic information, 
characteristics related to COVID-19, and behavior of compliance with COVID-19 measures.

Fear of COVID-19 Scale (FCV-19S): The Turkish validity study of the FCV-19S, developed by Ahorsu et al. (2020), was conducted by Satici et al. (2020). In the scale with one dimension and seven items, there was no reversely scored item. The total score from all items of the scale reflects the level of fear of COVID-19 that an individual experiences. The scores that can be taken from the scale range from 7 to 35 . The higher scores from the scale mean higher levels of the fear of COVID-19. The Cronbach's alpha value of the scale was found to be 0.894 in this study.

\section{Data collection}

The process of data collection in the study began on 05.15.2020, employed the online survey created using Google Forms, and was terminated on 06.01.2020, that is, when the first attempt of normalization in Turkey began.

\section{Data analysis}

The data obtained from the study was evaluated by using the Statistical Package for Social Sciences (SPSS) software program (version 22.0). Number and percentage distributions were presented as descriptive statistics. The Mann-Whitney $U$ Test, the Kruskal-Wallis Test, and the chi-squared test were used in the evaluation of nonparametric variables. In addition, multiple regression analysis was performed to assess the correlation of the fear of COVID-19. In addition, multiple regression analysis was performed to assess the correlation of the fear of COVID-19 with age, gender, having a relative with COVID-19, and losing any relative due to COVID-19. Reference categories were determined as being aged between 18 and 24 years, being male, not losing relatives, and not having any relative with COVID-19. The analysis of the service sector $(F=3.812, p<0.05)$ and the healthcare sector $(F=4.219, p<0.001)$ was carried out separately, and the explanatory power of the model was found to be $52 \%$ for the service sector and $43 \%$ for the healthcare sector.

\section{Results}

The age of the participants varied between 18 and 64, and the arithmetic mean of the ages was $30.68 \pm 9.49$ years for the workers from the service sector and $28.03 \pm 7.26$ years for the healthcare workers. More than half $(60.3 \%)$ of the healthcare workers were in the 18-26 age group. For the service sector, $73.8 \%$ of male participants and $1.2 \%$ of female participants were in this age group.

While no difference was found between occupational groups and the FCV-19S score in the service sector $(p=0.125)$, there was a significant correlation between occupational groups and the FCV-19S score in the healthcare sector $(p=0.015)$. The FCV-19S median value of midwives was 21 , and it was higher than those of other occupational groups were (Table 1).

The FCV-19S median value was 14 for the service sector and 17 for the healthcare sector. The mean FCV-19S score of the healthcare workers who responded, "I sometimes comply with rules and precautions," was very low when compared with those of the participants who fully

Table 1 Comparison of FCV-19S scores of service and healthcare sector workers based on occupational groups

\begin{tabular}{|c|c|c|c|c|c|}
\hline \multicolumn{6}{|l|}{ FCV-19S } \\
\hline & $n$ & Mean \pm SD & Median & $25-75 \%$ & $p$ \\
\hline Service sector & $(309)$ & & & & \\
\hline Office-workplace workers & 87 & $6.99 \pm .75$ & 16.00 & $11.00-21.00$ & $0.125^{*}$ \\
\hline Workers providing home services & 36 & $6.79 \pm 1.13$ & 12.00 & $8.25-18.50$ & \\
\hline Workers providing services for community at their workplaces & 160 & $6.69 \pm 0.53$ & 13.00 & $9.00-19.00$ & \\
\hline Community volunteers & 26 & $6.96 \pm 1.37$ & 12.50 & $9.00-20.25$ & \\
\hline Healthcare sector & $(426)$ & & & & \\
\hline Nurses & 307 & $17.83 \pm 6.87$ & 17.00 & $13.00-23.00$ & $0.015^{*}$ \\
\hline Midwives & 35 & $20.46 \pm 6.81$ & 21.00 & $15.00-26.00$ & \\
\hline Physicians & 13 & $20.34 \pm 10.18$ & 19.00 & $11.00-31.50$ & \\
\hline Emergency medical technicians and paramedics & 15 & $16.00 \pm 6.79$ & 14.00 & 10.00-20.00 & \\
\hline Technicians & 15 & $16.73 \pm 7.61$ & 15.00 & $8.00-25.00$ & \\
\hline Health officers & 12 & $16.83 \pm 6.09$ & 16.50 & $11.75-21.00$ & \\
\hline Medical secretaries/officers/patient admission staff & 11 & $14.91 \pm 5.52$ & 14.00 & $10.00-21.00$ & \\
\hline Other (managers, hospital cleaning staff) & 18 & $13.44 \pm 5.17$ & 13.50 & $8.00-16.25$ & \\
\hline
\end{tabular}

*Kruskal-Wallis test 
complied with the rules and those who strove to comply with them $(p<0.05)$. The mean FCV-19S scores of those who thought they had COVID-19 symptoms due to stress or panic were higher among the healthcare workers $(p<0.05)$. While the FCV-19S scores of those whose relatives had caught COVID-19 and whose relatives had died due to COVID-19 were higher among the healthcare workers, there was no statistical difference between them. However, for the service sector employees whose relatives had caught the virus $(p=0.003)$ and whose relatives had died due to COVID-19 $(p=0.001)$, the FCV-19S scores were higher. The FCV-19S scores of those whose overall wellbeing deteriorated when compared with previous months were found to be higher among the workers in both sectors ( $p<0.001$, and $p<0.001$, respectively). Likewise, the FCV-19S scores of those who did not have future concerns among the workers in both sectors were lower than those whose concerns increased or decreased $(p<0.001$ and $p<0.001$, respectively) (Table 2 ).

The number of those who said that they never used masks was three in the service sector, whereas there was no participant who gave this answer among the healthcare sector workers; the FCV-19S scores of the healthcare sector workers who said that they always used masks were higher $(p=0.014)$ (Table 3).

Similarly, there were five people in the service sector who indicated that they never washed their hands, whereas no one gave this answer in the healthcare sector. The FCV$19 \mathrm{~S}$ scores of the participants in the service sector who stated that they never washed their hands and those in the healthcare sector who indicated that they partially washed their hands were lower than those of the others $(p<0.05$ in both groups). The FCV-19S scores of the healthcare workers who never used gloves were lower than those of the others $(p=0.007)$. In addition, the FCV-19S scores of the healthcare workers who took a bath upon getting home $(p=0.023)$ and those who changed clothes upon getting home $(p=0.011)$ were higher (Table 3$)$.

Table 4 shows the impact of age, gender, loss of relatives due to COVID-19, and relatives' getting sick due to COVID-19 on the FCV-19S scores of healthcare and service sector employees. The FCV-19S scores of the women during the COVID-19 pandemic were found to be 2.77 times higher than those of men $(p<0.05)$. Similarly, having a relative who got sick due to COVID-19 increased the FCV-19S scores by 1.319 times $(p<0.05)$.

According to the results of the analysis in the healthcare sector, the FCV-19S scores of the participants aged 45 years and older were 4.041 times higher than those of participants in the 18-24 age group $(p<0.05)$. The FCV19S scores of the women during the COVID-19 pandemic were 2.595 times higher than those of men $(p<0.05)$.

\section{Discussion}

In this study, the fear of COVID-19 of the individuals who were actively working during the COVID-19 pandemic as well as their compliance with the preventive measures during the pandemic were investigated. In the study, the FCV-19S median score was found to be 14 for the healthcare workers and 17 for the service sector employees. The FCV-19S scores differed based on the profession and were higher among healthcare sector workers. When the findings from other countries were examined, it was found that the FCV-19S score of the nurses was 19.92 in the Philippines and that $63.2 \%$ of the nurses in China had strong fears (the scale scores between 30 and 40) and $28 \%$ had moderate fears (the score scores between 19 and 29) (Hu et al. 2020). In the present study, the FCV-19S scores of the healthcare workers were lower when compared with the scores in China despite variation in connection with other countries. It is believed that factors such as countries' readiness for the COVID-19 pandemic, ease of access to communication technologies, fast transmission of information, advanced health technology, health resources, achievements in the management of the pandemic contribute to lower levels of fear in this process. In fact, the first case in Turkey was reported approximately 3 months later than that in China. In this process, the scientific developments were monitored, and the Ministry of Health took the necessary measures by developing diagnosis, treatment, follow-up, and contact tracing procedures against a possible outbreak. Thus, it can be said that devoted and successful management work and readiness have prevented fear levels from increasing.

Healthcare workers are expected to experience more fear than all other professional groups. Lu et al. (2020) found that the rate of experiencing moderate and strong fear was higher among healthcare staff than that among the administrative staff (70.6 vs. 58.4\%). Chaudhary et al. 2020 found that almost $94 \%$ of oral health workers were in fear of getting infection compared to $51 \%$ non-clinical workers. In the present study, midwives were found to be more likely to experience fear than other health professionals were. In the literature, no such finding was reported for midwives, although it was reported that nurses experienced fear and that the healthcare staff working in the hospital experienced more fear than the administrative staff and that the healthcare staff who were in close contact with infected patients experienced more fear, anxiety, and depression than other non-clinical staff did ( $\mathrm{Hu}$ et al. 2020; Lu et al. 2020). Although the curriculum for midwifery focuses mainly on pregnancy and childbirth, they are often employed as nurses in hospitals in Turkey (Ministry of Health 2018). During the pandemic, even 


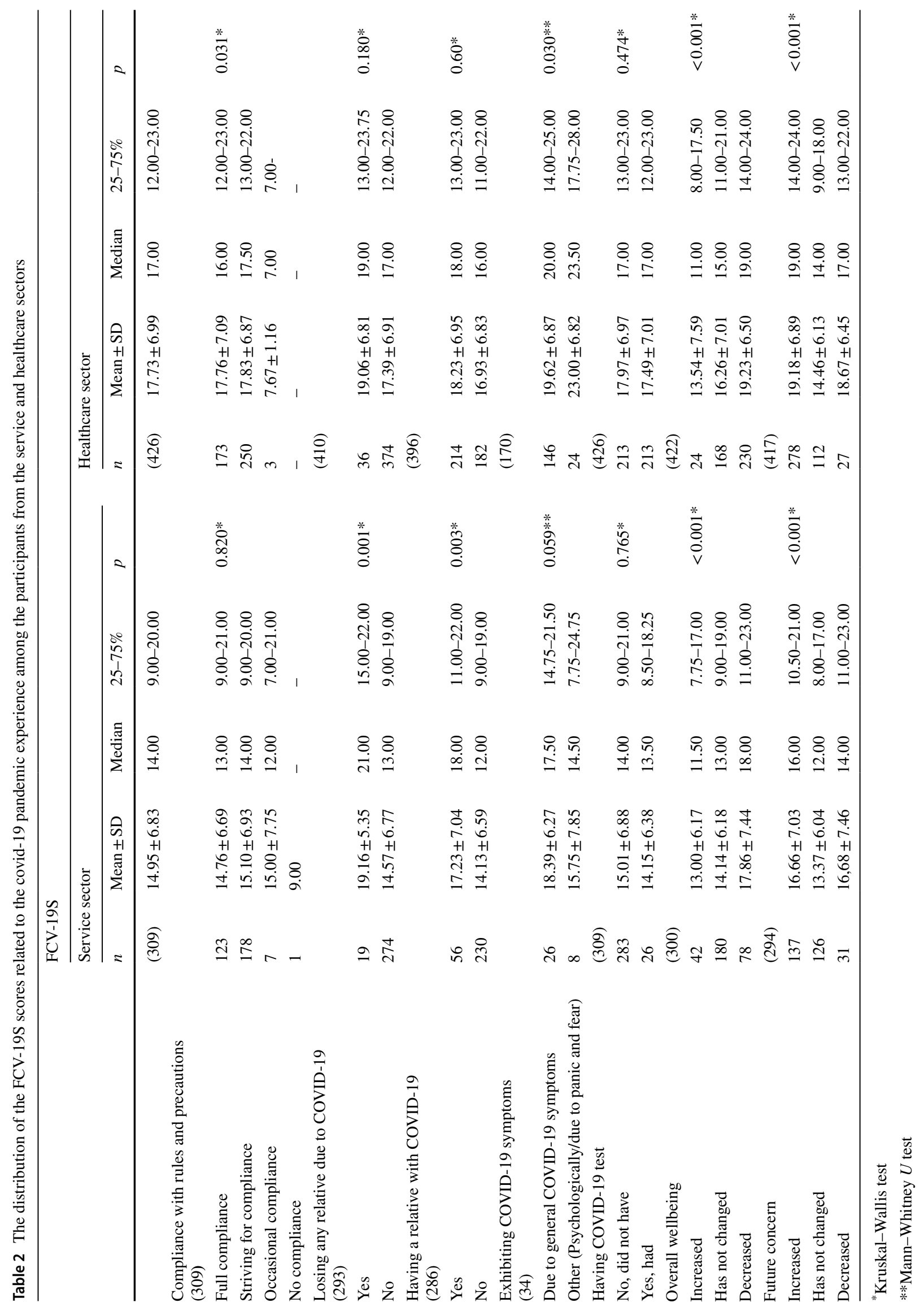


Table 3 Distribution of the FCV-19S scores related by preventive measures taken during the pandemia among the participants from the service and healthcare sectors

\begin{tabular}{|c|c|c|c|c|c|c|c|c|c|c|}
\hline & \multicolumn{10}{|c|}{ FCV-19S } \\
\hline & \multicolumn{5}{|c|}{ Service sector } & \multicolumn{5}{|c|}{ Healthcare sector } \\
\hline & $n$ & Mean \pm SD & Median & $25-75 \%$ & $p$ & $n$ & Mean \pm SD & Median & $25-75 \%$ & $p$ \\
\hline \multicolumn{11}{|l|}{ Using a mask } \\
\hline No compliance & 3 & $8.67 \pm 2.89$ & 7.00 & 7.00 & $0.298^{*}$ & - & - & - & - & $0.014 *$ \\
\hline Partial compliance & 32 & $14.00 \pm 6.34$ & 12.00 & $9.00-20.50$ & & 5 & $13.80 \pm 2.95$ & 14.00 & $11.50-16.00$ & \\
\hline Moderate compliance & 46 & $14.15 \pm 7.17$ & 12.00 & $7.00-21.00$ & & 23 & $15.00 \pm 7.09$ & 13.00 & $9.00-22.00$ & \\
\hline Usual compliance & 74 & $15.78 \pm 6.98$ & 15.00 & $9.00-21.00$ & & 71 & $16.24 \pm 6.74$ & 15.00 & $10.00-20.00$ & \\
\hline Full compliance & 145 & $14.95 \pm 6.82$ & 14.00 & $9.00-19.00$ & & 324 & $18.29 \pm 6.94$ & 18.00 & $13.00-23.00$ & \\
\hline \multicolumn{11}{|l|}{ Washing hands } \\
\hline No compliance & 5 & $8.40 \pm 2.19$ & 7.00 & $7.00-10.50$ & $0.006^{*}$ & - & - & - & - & $0.043 *$ \\
\hline Partial compliance & 16 & $12.44 \pm 5.65$ & 10.50 & $7.50-17.00$ & & 6 & $11.33 \pm 4.23$ & 11.50 & $7.00-14.75$ & \\
\hline Moderate compliance & 39 & $13.03 \pm 6.56$ & 11.00 & $7.00-17.00$ & & 16 & $15.88 \pm 6.39$ & 16.00 & $9.50-19.75$ & \\
\hline Usual compliance & 69 & $14.46 \pm 6.26$ & 14.00 & $9.00-18.00$ & & 63 & $16.86 \pm 6.96$ & 16.00 & $12.00-22.00$ & \\
\hline Full compliance & 167 & $15.78 \pm 7.17$ & 15.00 & $10.00-21.00$ & & 332 & $18.08 \pm 6.96$ & 18.00 & $13.00-23.00$ & \\
\hline \multicolumn{11}{|l|}{ Using gloves } \\
\hline No compliance & 55 & $14.80 \pm 7.36$ & 12.00 & $9.00-21.00$ & $0.492 *$ & 35 & $14.74 \pm 5.62$ & 14.00 & $10.00-19.00$ & $0.007 *$ \\
\hline Partial compliance & 57 & $13.14 \pm 5.14$ & 12.00 & $9.00-18.00$ & & 48 & $16.81 \pm 5.87$ & 17.00 & $13.00-20.00$ & \\
\hline Moderate compliance & 62 & $15.15 \pm 6.28$ & 14.00 & $10.00-19.00$ & & 54 & $15.85 \pm 6.21$ & 15.00 & $10.75-22.00$ & \\
\hline Usual compliance & 65 & $15.92 \pm 8.02$ & 16.00 & $8.50-21.50$ & & 113 & $18.89 \pm 7.63$ & 18.00 & $13.00-25.00$ & \\
\hline Full compliance & 60 & $14.68 \pm 6.51$ & 14.00 & $9.25-19.00$ & & 172 & $18.34 \pm 6.97$ & 18.50 & $13.00-24.00$ & \\
\hline \multicolumn{11}{|c|}{ Taking a bath when coming home } \\
\hline No compliance & 11 & $13.64 \pm 6.09$ & 12.00 & $7.00-21.00$ & $0.220 *$ & 2 & $8.00 \pm 1.41$ & 8.00 & 7.00 & $0.023 *$ \\
\hline Partial compliance & 49 & $12.78 \pm 5.57$ & 11.00 & $8.00-17.50$ & & 19 & $15.37 \pm 7.13$ & 14.00 & $9.00-22.00$ & \\
\hline Moderate compliance & 72 & $15.75 \pm 6.89$ & 15.00 & $10.00-21.00$ & & 46 & $16.37 \pm 6.08$ & 15.50 & $11.75-22.00$ & \\
\hline Usual compliance & 87 & $15.15 \pm 6.88$ & 13.00 & $9.00-21.00$ & & 104 & $16.97 \pm 6.65$ & 16.00 & $12.00-22.00$ & \\
\hline Full compliance & 81 & $15.02 \pm 7.46$ & 13.00 & $8.00-20.00$ & & 246 & $18.44 \pm 7.07$ & 18.00 & $13.00-24.00$ & \\
\hline \multicolumn{11}{|c|}{ Changing clothes when coming home } \\
\hline No compliance & 8 & $11.88 \pm 7.16$ & 8.00 & $7.00-18.75$ & $0.337 *$ & 1 & 7.00 & 7.00 & 7.00 & $0.011 *$ \\
\hline Partial compliance & 28 & $12.82 \pm 5.61$ & 11.00 & $8.25-17.50$ & & 10 & $12.70 \pm 5.64$ & 11.00 & $9.00-14.75$ & \\
\hline Moderate compliance & 55 & $14.67 \pm 6.49$ & 14.00 & $9.00-20.00$ & & 19 & $15.53 \pm 6.45$ & 15.00 & $11.00-19.00$ & \\
\hline Usual compliance & 61 & $13.74 \pm 6.53$ & 11.00 & $9.00-17.00$ & & 67 & $16.7 \pm 7.17$ & 16.00 & $10.00-23.00$ & \\
\hline Full compliance & 146 & $15.82 \pm 7.13$ & 15.00 & $9.75-21.00$ & & 319 & $18.19 \pm 6.85$ & 18.00 & $13.00-23.00$ & \\
\hline \multicolumn{11}{|c|}{ Social distancing with clients/patients } \\
\hline No compliance & 11 & $14.90 \pm 8.61$ & 11.00 & $7.00-21.00$ & $0.955^{*}$ & 8 & $13.13 \pm 5.82$ & 11.50 & $7.50-19.25$ & $0.150 *$ \\
\hline Partial compliance & 25 & $14.30 \pm 6.82$ & 12.00 & $8.00-19.00$ & & 29 & $18.56 \pm 8.01$ & 16.00 & $12.50-26.50$ & \\
\hline Moderate compliance & 61 & $14.51 \pm 6.59$ & 13.00 & $7.50-21.00$ & & 40 & $15.83 \pm 6.09$ & 15.00 & $10.25-20.00$ & \\
\hline Usual compliance & 75 & $14.69 \pm 6.47$ & 14.00 & $10.00-18.00$ & & 99 & $18.23 \pm 6.82$ & 18.00 & $14.00-23.00$ & \\
\hline Full compliance & 125 & $15.26 \pm 7.19$ & 14.00 & $9.00-20.00$ & & 220 & $17.82 \pm 7.04$ & 17.00 & $12.00-23.00$ & \\
\hline \multicolumn{11}{|c|}{ Social distancing with colleagues } \\
\hline No compliance & 22 & $14.82 \pm 7.27$ & 13.00 & $8.00-21.25$ & $0.171^{*}$ & 15 & $13.33 \pm 5.68$ & 12.00 & $7.00-19.00$ & $0.075 *$ \\
\hline Partial compliance & 27 & $12.67 \pm 6.43$ & 11.00 & $7.00-18.00$ & & 37 & $18.38 \pm 7.03$ & 17.00 & $14.00-23.50$ & \\
\hline Moderate compliance & 68 & $14.09 \pm 6.63$ & 12.00 & $8.25-20.25$ & & 88 & $17.17 \pm 6.29$ & 17.00 & $13.00-22.00$ & \\
\hline Usual compliance & 76 & $15.29 \pm 6.71$ & 14.50 & $9.25-19.00$ & & 134 & $18.59 \pm 6.98$ & 18.00 & $13.00-23.00$ & \\
\hline Full compliance & 102 & $15.69 \pm 6.95$ & 15.00 & $9.75-20.00$ & & 141 & $17.72 \pm 7.45$ & 16.00 & $12.00-23.50$ & \\
\hline \multicolumn{11}{|c|}{ Using disinfectant/cologne } \\
\hline No compliance & 9 & $17.78 \pm 9.15$ & 18.00 & $8.00-27.00$ & $0.112 *$ & - & - & - & - & $0.055^{*}$ \\
\hline Partial compliance & 18 & $11.22 \pm 4.72$ & 10.50 & $7.00-13.25$ & & 10 & $12.50 \pm 6.38$ & 10.50 & $7.75-14.75$ & \\
\hline Moderate compliance & 55 & $14.09 \pm 6.30$ & 12.00 & $8.00-21.00$ & & 38 & $16.58 \pm 6.70$ & 16.00 & $10.75-22.00$ & \\
\hline
\end{tabular}


Table 3 (continued)

\begin{tabular}{|c|c|c|c|c|c|c|c|c|c|c|}
\hline & \multicolumn{10}{|c|}{ FCV-19S } \\
\hline & \multicolumn{5}{|c|}{ Service sector } & \multicolumn{5}{|c|}{ Healthcare sector } \\
\hline & $n$ & Mean \pm SD & Median & $25-75 \%$ & $p$ & $n$ & Mean \pm SD & Median & $25-75 \%$ & $p$ \\
\hline Usual compliance & 64 & $15.00 \pm 7.08$ & 14.00 & $9.00-19.00$ & & 92 & $18.15 \pm 7.15$ & 17.00 & $13.25-22.00$ & \\
\hline Full compliance & 153 & $15.36 \pm 6.94$ & 14.00 & $9.00-20.50$ & & 272 & $17.87 \pm 6.90$ & 17.00 & $12.00-23.00$ & \\
\hline
\end{tabular}

*Kruskal-Wallis test

non-clinical health workers were assigned to active combat against the disease. In this regard, it is suggested that the midwives' lack of knowledge of medical treatment, care, and infection control has played a role in their having more fear than nurses. Indeed, the lack of experience concerning infectious diseases was reported as the cause of fear among the nurses working in risky places (frontline) have no experience of infectious diseases as a cause of fear during the COVID-19 outbreak in China (Hu et al. 2020). Midwives were followed by physicians as health workers with a high level of fear. As a professional group that first encounters the patient population, diagnoses, and follows up the case, physicians work under uncertainty, which can exacerbate their fears.

The healthcare workers were characterized by a high level of compliance with precautionary measures because of the conditions they were working in. A study in China reported that $85 \%$ of healthcare workers were fearful of infection with the disease and that $89.7 \%$ adhered to preventive measures (Zhang et al. 2020). In Thailand, 95.6\% of healthcare workers washed their hands, $93.1 \%$ used masks and personal protective equipment, $82 \%$ practiced social distancing in hospital, and $78 \%$ practiced social distancing in society as compliance with precautions (Apisarnthanarak et al. 2020). In Afghanistan, it was observed that $98 \%$ of healthcare workers used gloves and masks, $76 \%$ used disposable aprons, $83 \%$ used eye protection, $94 \%$ washed their hands regularly, and $63 \%$ used N95 facemasks as part of the pandemic measures (Raghavan et al. 2020). However, during the Middle East Respiratory Syndrome (MERS) outbreak as a previous pandemic, the level of compliance with measures such as handwashing (60.3\%), using surgical masks, or using N95 masks if necessary (less than half of the participants) by healthcare workers was lower when compared with the measures taken during the COVID-19 pandemic (Alsahafi and Cheng 2016). It is argued that this was because COVID-19 spreads faster than the MERS pathogen.

In the literature, it was reported that as a reduction in risky behavior, fear ensured greater compliance with preventive strategies such as social distancing and handwashing and the use of masks and personal protective equipment (Apisarnthanarak et al. 2020; Cawcutt et al. 2020; Harper et al. 2020; Oh et al. 2020; Sasaki et al. 2020). In the present study, there was a significant correlation between the level of fear and the behavior of compliance with precautions in the healthcare workers. The level of fear was the lowest in those who reported rare compliance with measures. Among the healthcare workers, there was no one who did not wash hands at all or wear a mask when necessary. However, there were individuals who did not wear a mask (1\%) or did not wash hands when necessary (1.6\%) among the service sector employees. This difference between occupational groups in terms of compliance with precautions is believed to be due to the obligation to use masks and gloves in hospitals, sociodemographic variables, knowledge about the disease, direct contact with patients, risk perceptions, and the resulting fear-related behavior change with regard to adherence to measures.

It is important that individuals should not experience the fear of COVID-19 at the level of panicking. It is believed that both insubstantial and exaggerated fear negatively affects mental health. Indeed, among the workers in both sectors, the fear of COVID-19 of those whose wellbeing declined in comparison with that in the past was found to be high. In addition, the healthcare workers who fallaciously reported to have COVID-19 symptoms experienced more fear than those who exhibited COVID-19 symptoms. In this regard, it is believed that it is critical to control the level of fear in employees.

In the present study, the regression model established to test the effect of age, gender, losing relatives due to COVID-19, and having relatives with COVID-19 on the fear of COVID-19 was statistically significant. Despite demographic differences, the fear of COVID-19 and the behavior of preventive intervention are more likely to allow a person to develop the ability to cope. Fear can accelerate the adoption of COVID-19-preventive behaviors. These results are supported by the effect of fear and demographic factors on the levels of preventive behaviors of individuals in the current literature (Gamma 2019). As age increased in the healthcare workers, the level of fear increased. It is believed that this was because the healthcare workers were able to assess well the relationship between advanced age and mortality because of COVID-19. In both sectors, 


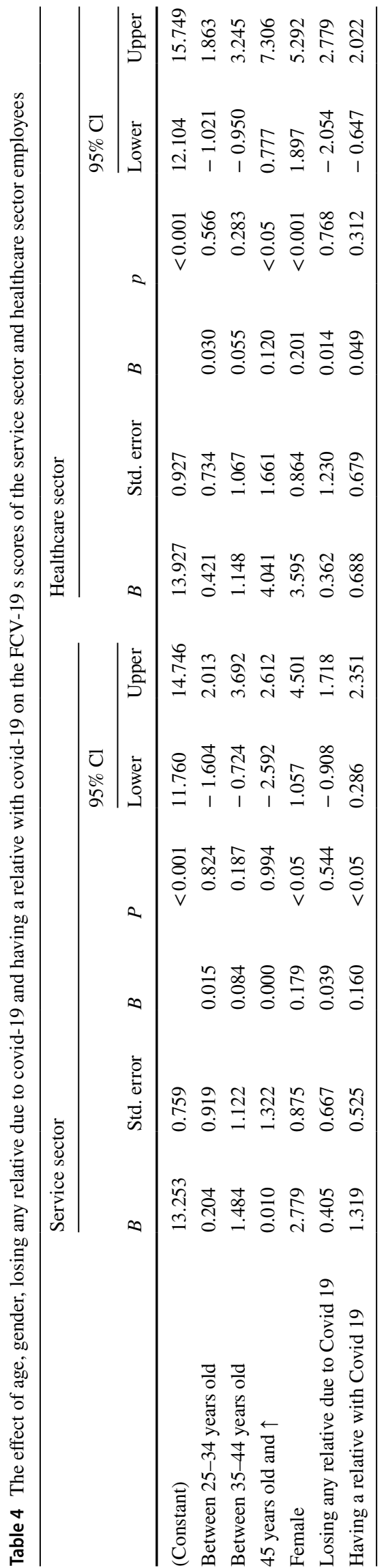

gender appeared to have an effect on the fear of COVID-19. Women experience more fear when compared with men. Yet, although the risk of death due to COVID-19 is higher for men than that for women (Caramelo et al. 2020; Jin et al. 2020), women perceived themselves at greater risk. Similar results were reported in the literature (Bitan et al. 2020; Reznik et al. 2020; Sakib et al. 2020; Saleem et al. 2020; Yildırım et al. 2020; Zhong et al. 2020).

\section{Conclusion}

There was a significant correlation between having or losing relatives with COVID-19 and the fear of COVID-19 among the service sector employees, whereas this correlation was not significant among the healthcare workers. During the pandemic, the healthcare workers were isolated from their families, but the workers in other sectors continued to stay in their own houses. In this regard, the fear of infecting relatives or losing relatives may have caused more fear in the service sector employees. These results help us determine the relationship between the fear experienced by healthcare workers and workers in other sectors during the pandemic and their compliance with preventive measures. The healthcare workers need more support in fear management than those engaged in other professions did, and it is recommended that raising the awareness of service sector employees in terms of compliance with preventive measures should be prioritized.

\section{Limitations}

The sample group does not fully represent the working population in the country. The study does not contain multifaceted measurements or assessments of the emotional aspects of social norms and values regarding the fear of COVID- 19 . Another limitation of the study is that the results obtained from the research were obtained from the self-reports of the participants.

Acknowledgements This study was funded by the Yildırım Beyazıt University Scientific Research Projects Coordination Unit within the scope of this study (ID:2109). The authors would like to acknowledge the participant for their contribution to the study.

Author contributions EK designed the article. EK and AA conducted the research data collecting. FÖ analysed the data. EK drafted the manuscript with contributions and reviews from FÖ, AA and HÖ. All contributors have given final approval of the version to be published.

Funding This study is funded by Ankara Yıldırım Beyazıt University, Scientific Researc Project (ID:2109). 


\section{Declarations}

Conflict of interest The authors declare no competing interests.

Ethical approval Ethical approval from Ethics Commission of Yıldırım Beyazit University in Ankara (84892257-604.01.02-E.15646) and necessary permits from the Ministry of Health have been obtained through an online application. Participation in the study was voluntary.

\section{References}

Ahorsu DK, Lin CY, Imani V, Saffari M, Griffiths MD, Pakpour AH (2020) The fear of COVID-19 scale: development and initial validation. Int J Ment Health Addict. https://doi.org/10.1007/s11469020-00270-8 (Pubmed: 32226353)

Alsahafi AJ, Cheng AC (2016) Knowledge, attitudes and behaviours of healthcare workers in the Kingdom of Saudi Arabia to MERS coronavirus and other emerging infectious diseases. Int J Environ Res Public Health 13:1214. https://doi.org/10.3390/ijerph1312 1214 (Pubmed: 27929452)

Apisarnthanarak A, Apisarnthanarak P, Siripraparat C, Saengaram P, Leeprechanon N, Weber DJ (2020) Impact of anxiety and fear for COVID-19 toward infection control practices among Thai healthcare workers. Infect Control Hosp Epidemiol. https://doi.org/10. 1017/ice.2020.280 (Pubmed: 32507115)

Bitan DT, Grossman-Giron A, Bloch Y, Mayer Y, Shiffman N, Mendlovic S (2020) Fear of COVID-19 scale: psychometric characteristics, reliability and validity in the Israeli population. Psychiatry Res 289:113100

Caramelo F, Ferreira N, Oliveiros B (2020) Estimation of risk factors for COVID-19 mortality-preliminary results. https://doi.org/10. 1101/2020.02.24.20027268

Cawcutt KA, Starlin R, Rupp ME (2020) Fighting fear in healthcare workers during the COVID-19 pandemic. Infect Control Hosp Epidemiol. https://doi.org/10.1017/ice.2020.315 (Pubmed: 32580790)

Chaudhary FA, Ahmad B, Ahmad P, Khalid MD, Butt DQ, Khan SQ (2020) Concerns, perceived impact, and preparedness of oral healthcare workers in their working environment during COVID19 pandemic. J Occup Health 62(1):e12168

Gamma A (2019) Ebola prevention research: The role of threat in ebola prevention behaviours. Dissertation, University of Zurich

Harper CA, Satchell LP, Fido D, Latzman RD (2020) Functional fear predicts public health compliance in the COVID-19 pandemic. Int J Ment Health Addict. https://doi.org/10.1007/s11469-020-002815 (Pubmed: 32346359)

Hu D, Kong Y, Li W, Han Q, Zhang X, Zhu LX, He HG (2020) Frontline nurses' burnout, anxiety, depression, and fear statuses and their associated factors During the COVID-19 outbreak in Wuhan, China: A large-scale cross-sectional study. EClinicalMedicine 24. doi: 10.1016/j.eclinm.2020.100424

Jin J-M, Bai P, He W, Wu F, Liu X-F, Han D-M, Liu S, Yang J-K (2020) Gender Differences in Patients With COVID-19: Focus on Severity and Mortality. Front Public Health 8:152. https://doi. org/10.3389/fpubh.2020.00152

Lu W, Wang H, Lin Y, Li L (2020) Psychological status of medical workforce during the COVID-19 pandemic: a cross-sectional study. Psychiatry Res 288:112936. https://doi.org/10.1016/j.psych res.2020.112936
Ministry of Health (2018) Health statistics annual. https://www.sagli kaktuel.com/d/file/36134,siy2018trpdf.pdf

Ogolodom MP, Mbaba AN, Alazigha N, Erondu OF, Egbe NO et al (2020) Knowledge, attitudes and fears of HealthCare workers towards the corona virus disease (COVID-19) pandemic in SouthSouth. Nigeria Health Sci J SP Iss 1:002

Oh SH, Lee SY, Han C (2020) The effects of social media use on preventive behaviors during infectious disease outbreaks: the mediating role of self-relevant emotions and public risk perception. Health Commun https://doi.org/10.1080/10410236.2020.1724639

Pakpour AH, Griffiths MD (2020) The fear of COVID-19 and its role in preventive behaviors. J Concurrent Disord 2(1): 58-63.

Raghavan V, Jabbarkhail N, Ahmady A (2020) Health worker's perception survey on COVID-19: knowledge, perception, and practice survey of health workers in eight provinces of Afghanistan. https://reliefweb.int/sites/reliefweb.int/files/resources/Health_ Worker_s_Perception_Survey_FInal_20052020.pdf

Reznik A, Gritsenko V, Konstantinov V, Khamenka N, Isralowitz R (2020) COVID-19 fear in Eastern Europe: validation of the fear of COVID-19 scale. Int J Ment Health Addict. https://doi.org/10. 1007/s11469-020-00283-3 (Pubmed: 32406404)

Rohrmann B (2008) Risk perception, risk attitude, risk communication, risk management: a conceptual appraisal. In: Proceedings of the international emergency management society annual conference, Prague, Czech Republic, 17-19 June 2008

Sakib N, Bhuiyan AKMI, Hossain S, Al Mamun F, Hosen I, Abdullah AH, Sarker MA, Mohiuddin MS, Rayhan I, Hossain M, Sikder MT, Gozal D, Muhit M, Islam SMS, Griffiths MD, Pakpour AH, Mamun MA (2020) Psychometric validation of the Bangla Fear of COVID-19 Scale: confirmatory factor analysis and Rasch analysis. Int J Ment Health Addict. https://doi.org/10.1007/s11469-02000289-x (Pubmed: 32395096)

Saleem Z, Majeed MM, Rafique S, Siqqiqui Z, Ghandhi D, Tariq H (2020) COVID-19 pandemic fear and anxiety among healthcare professionals in Pakistan. Res Sq. https://doi.org/10.21203/ rs.3.rs-37608/v2

Sasaki N, Kuroda R, Tsuno K, Kawakami N (2020) Fear, worry and workplace harassment related to the COVID-19 epidemic among employees in Japan: prevalence and impact on mental and physical health. Available at SSRN 3569887

Satici B, Gocet-Tekin E, Deniz ME, Satici SA (2020) Adaptation of the Fear of COVID-19 Scale: Its association with psychological distress and life satisfaction in Turkey. Int J Ment Health Addict 1-9. https://doi.org/10.1007/s11469-020-00294-0

Yıldırım M, Geçer E, Akgül Ö (2020) The impacts of vulnerability, perceived risk, and fear on preventive behaviours against COVID19. Psychol Health Med. https://doi.org/10.1080/13548506.2020. 1776891

Zhang M, Zhou M, Tang F, Wang Y, Nie H, Zhang L, You G (2020) Knowledge, attitude and practice regarding COVID-19 among health care workers in Henan, China. J Hosp Infect 105:183-187. https://doi.org/10.1016/j.jhin.2020.04.012 (Pubmed: 32278701)

Zhong BL, Luo W, Li HM, Zhang QQ, Liu XG, Li WT, Li Y (2020) Knowledge, attitudes, and practices towards COVID-19 among Chinese residents during the rapid rise period of the COVID19 outbreak: a quick online cross-sectional survey. Int J Biol Sci 16:1745-1752. https://doi.org/10.7150/ijbs.45221 (Pubmed: 32226294)

Publisher's Note Springer Nature remains neutral with regard to jurisdictional claims in published maps and institutional affiliations. 